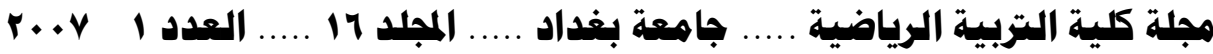

اثر التصور الذهني في تعلم دقة الإرسال المواجه من ( التنس ) بالكرة الطائرة

الأعلى

\section{بحث تجريبي}

على طلاب المرحلة الثانية في كلية التربية الرياضية بجامعة بغداد

د. باهـــرة علــــوان د. أسـماء حكمت فاضل

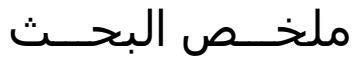

يشكل التصور الذهني في الكرة الطائرة احد الأسس المهـــة الموأثرة في نتـائج الأداء، ويشكل خاص في مهارة الإرسال ،لاسيما وان كثير من اللاعبين يبني قراره على موقع المنـافس وأسلوب تحركـه عند أداء هذه المهارة، بحيث يجعل من كل المؤثرات التي في ذهنه حدثا محددا لاتخاذ قراره في تحديا التصور المطلوب لسرعة ومكان الكرة ويما يحقى نتائج ذات طابع متقدم في الأداء. ولكون إن كثير من الطلبة لا يجيدون هذا النوع من الأداء ويالنظر لكون هذا الجانب من القدرة

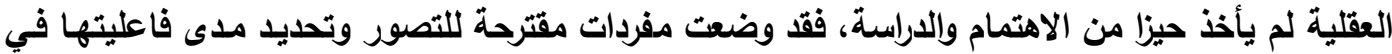
تطور هذه المهارة، كون ان إجادتها يؤثثر ايجابيا في نتائج الانجاز. وهلف البحث إلىى: 1. وضع منهج تعليمي باستخدام التصور الذهني في تعلم دقة الإرسـال المواجه من الأعلى بالكرة الطائرة

r. التعرف على تأثير التصور الذهني في تعلم دقة الإرسال المواجه من الأعلى بالكرة الطائرة.

$$
\text { وتمثلت فروض البحث بـ : }
$$

1. للمنهج التعليمي المقترح اثر ايجابي في تنمية التصور الذهني وتعلم دقة الإرسـال المواجه من الأعلى بالكرة الطائرة. 


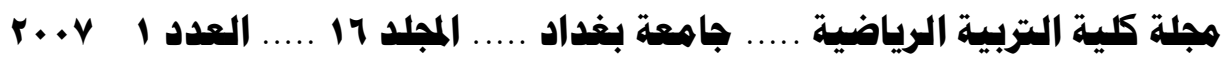

r. وجود فروق ذات دلالـة إحصـائية بين نتائج الاختبارات القبلية والبعديـة للمجموعتين التجريبية

$$
\text { والضابطة. }
$$

ولقد استخدم المنهج التجريبي في البحث وتكونت العينة من ( • ؛ ) طالبا، وقد أظهرت النتائج وجود

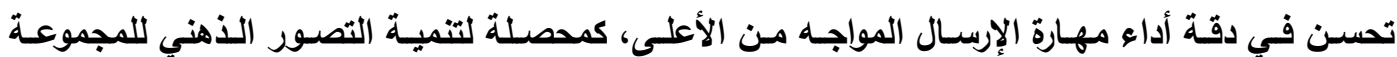

\section{Abstract}

Mental imagery in volleyball is considered one of the most effective bases for good performance.

This is true especially in serving where the player builds his reaction from the position of his opponent, his style of moving while performing this skill all give indicators to his mind to take the correct dicession in regard of speed of the ball and its position.

Most students cant perform mental imagery because it depends on cognitive ability that was not studied. The researcher proposed program used for specifying the effectively of developing this skill and finding if mastering it would positively affect achievement.

Aims of the study:

- designing a teaching program using mental imagery in learning the accuracy of serving in volleyball.

- Identifying the effect of mental imagery in learning the accuracy of serving in volleyball.

The hypothesis of the study:

1-The proposed teaching program has a positive effect in improving mental imagery and learning the accuracy of serving in volleyball.

2-There are statistical differences between are and post test for both group.

The researcher used the experimental method

The subjects were (40) students. The results showed improvement in the accuracy of performance as a result of improving mental imagery for the experimental group
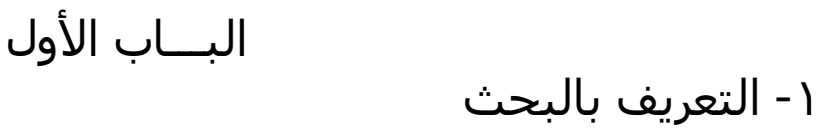


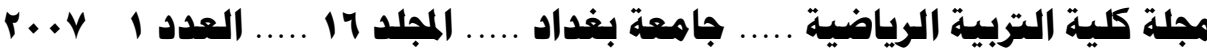

\section{| - المقدمة وأهمية البحث}

لقد شـهت الألعاب الرياضية خـلال السنوات الماضية تطورا كبيرا في الأداء الرياضي في كافة مفاصله ، لكون آن البحث العلمي المستمر قـ أضـاف الكثير من المفـاهيم لهذه الرياضـة ، وكان للكرة الطائرة حصة كبيرة في هذا المجال لكونها استفادت من البحوث العلمية لجميع الألعاب الفرقية وتداخلت في النتائج العامة ، وشكل ذلك إضافة نوعية لتطور هذه الفعالية ، وفي هذا المجال يعتبر التصور الذهني واحدا من الأمور المهمة التي أصبحت تؤثر على نتائج المباريات وخاصـة في مهارة الإرسـال المواجه من

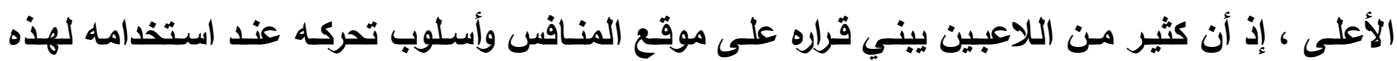
المهارة ، بحيث يجعل مـن كل المؤشـرات التي في ذهنـه حدثا محددا لاتخـاذ قراره في تحديد التصـور المطلوب لسرعة ومكان الكرة ، وعلى الرغم من صعويته ، ألا أن تعلمه والعمل المستمر من خلال التدريب الفاعل سيؤثر بشكل إيجابي في نتائج المباريات . وضمن ذلك تأتي أهمية البحث في بيان أهمية التصور الذهني في تعلم دقة الأداء المهاري للى لـى طلاب المرحلة الثانية مساهمة للارتقاء بمستوى الإنجاز الرياضي في ميدان الكرة الطائرة .

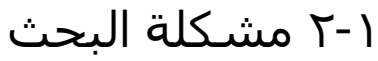
تتحدد مشكلة البحث في دراسة إمكانية تعلم مهارة الإرسال المواجه من الأعلى من خلال استخدام سياقات علمية في مجال التعلم الحركي والمهاري ، لكون أن تعلم إجادة هذا النوع من الإرسال

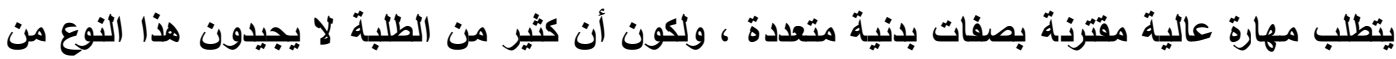
الاداء ، ويالنظر لكون هذا الجانب من القدرة العقلية لم يأخذ حيزا من الاهتمام والدراسة فقد وضعت من فئه مفردات مقترحة للتصور وتحديد مدى فاعليتها في تطور هذه المهارة ، والتي اصبحت إحدى الحلقات الضرورية ، لان أجادتها قد يحم الكثير من النتائج سواء أكان في نجاح دقة الإرسال أو في استقبال الخصم عندما يكون في موقع محدد وغير مهيأ لاستقبال هذا النوع من الإرسال ويالتالي ستكون المناولة

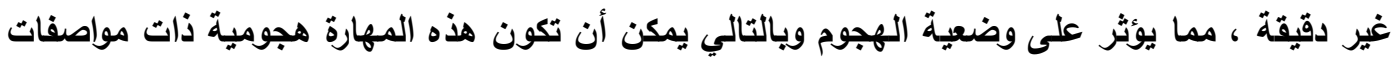

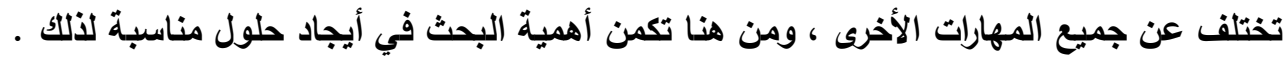

$$
\text { ا يـاف أهداف البحث }
$$




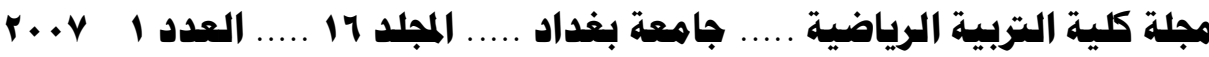

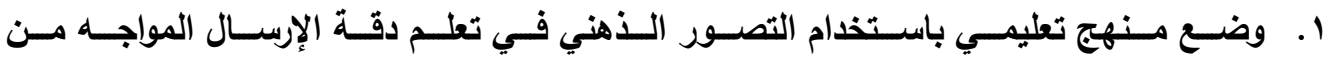

الأعلى بالكرة الطائرة.

r. التعرف على تأثير التصور الذهني في تعلم دقة الإرسـال المواجه من الأعلى بالكرة الطائرة .

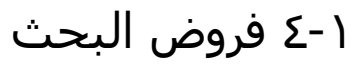

1. للمنهج التعليمي المقترح اثر إيجابي في تنمية التصور الذهني وتعلم دقة الإرسـال المواجه من

$$
\text { الأعلى بالكرة الطائرة }
$$

r. وجود فروق ذات دلالـة إحصائية بين نتائج الاختبـارات القبليـة والبعديـة للمجموعتين التجريبية

والضابطة ولصالح الاختبارات البعدية وللمجموعة التجريبية .

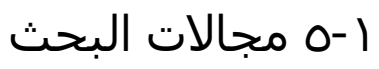

1 - - 1 المجال البشري: طلاب المرحلة الثانية في كلية التربية الرياضية بجامعة بغداد .

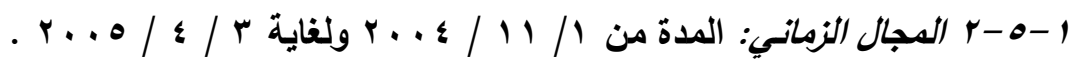

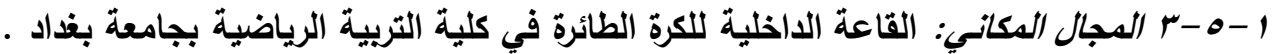

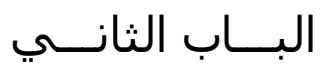

ץ- الدراسات النظرية

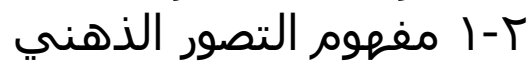

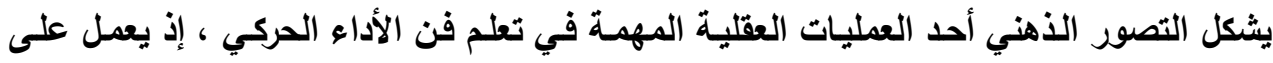

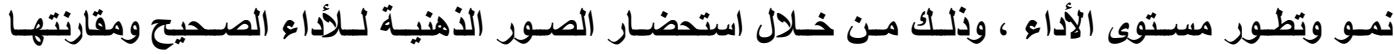
بالاستجابة ، بهدف ضبط وتنظيم التصرف بثكل دقيق ويما يحقق نتائج إيجابية أثناء الأداء . 


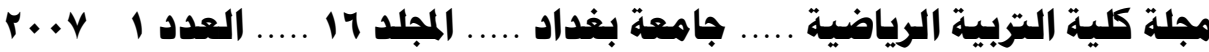

فالتصور الذهني يعني " الصورة التي يتخذها المتعلم عن طريق النظر والثرح والتوضيح للحركة

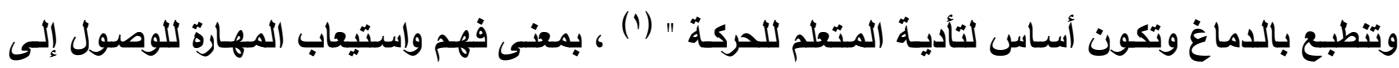
الأداء الأمثل عبر ما هو مكون من صور للأداء الحركي .

كذلك هو " استحضـار أو تذكر أحداث أو خبرات سـابقة أو استحضـار أحداث لـم يسبق حدوثئها

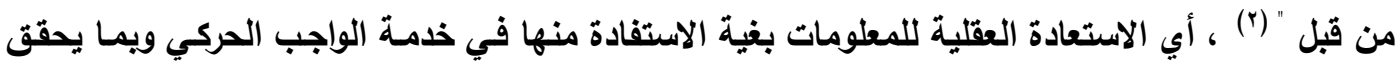
الوصول إلى الإنجاز المؤثر من فئماده

وأيضـا يمثل " عمليـة الأداء ذهنيا قبل الأداء الفعلـي للمهارة أو أثنـاء فترة الراحـة أو بعد الأداء

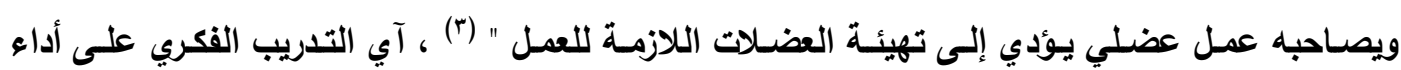
المهارة مما يؤدي إلى حدوث استجابات عصبية عضلية مماثلة للاستجابة الفعلية .

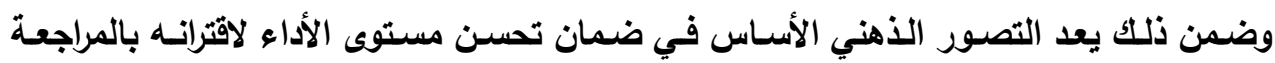

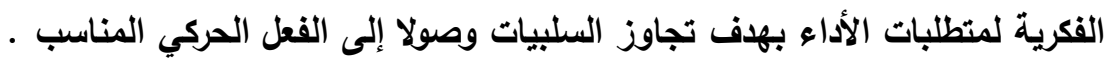

ץ-ץ أهمية التصور الذهني في مهارة الإرسال

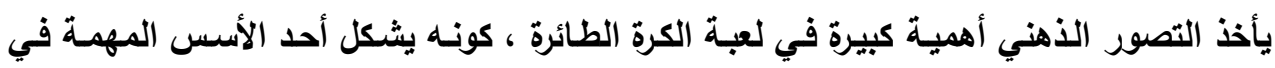

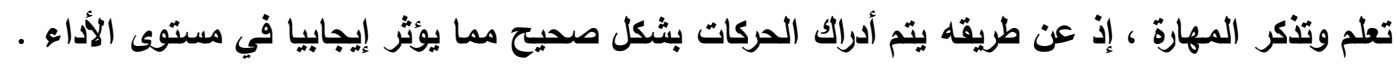

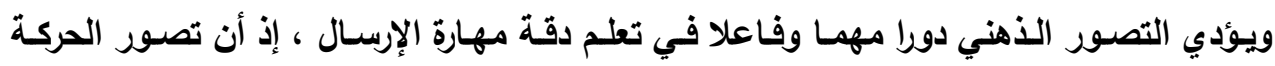

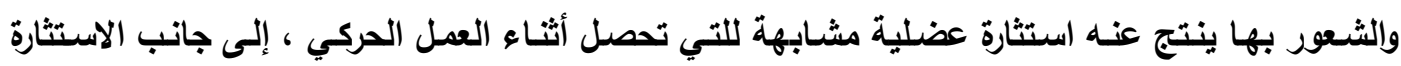
العصبية التي تساعد في حدوث التغذية الراجعة الحسية مما يسهم في تقويم وتعديل الاستجابة ، لاسيما

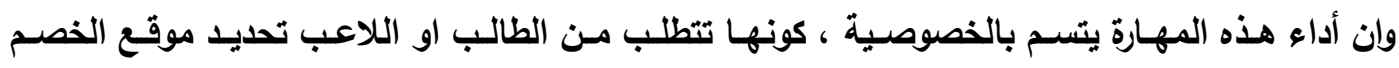
وإستراتيجية حركته لتحديد مكان سقوط الكرة فضلا عن تحديد المسافة والارتفاع ، وتلكك محددات تقترن

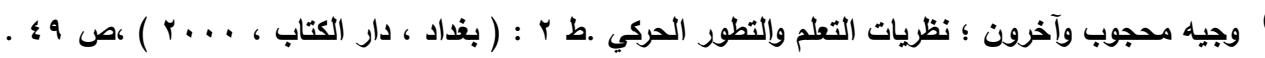
(') (2)Mccaffery\& orlick,T .Mental factors related to excellence among top professional golfers.international journal of sport psychology, 20, 1989, p. 256-278.

(") رويرت نادفير؛ (ترجمة) دليل الرياضيين للتدريب الذهني. محمد رضا( واخرون) : ( الموصل، مطبعة دار الحكمة للطباعة

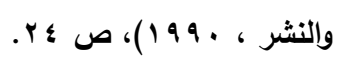




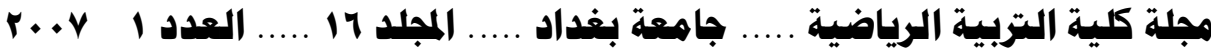

بسرعة ودقة استيفاء المعلومات التي تمنح الطالب او اللاعب إمكانية تصور المهارة وتحليلها ذهنيا " إذ

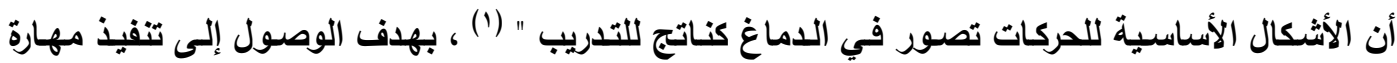

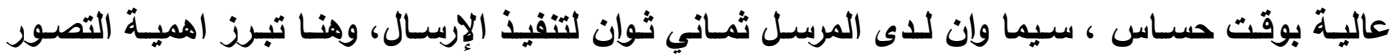

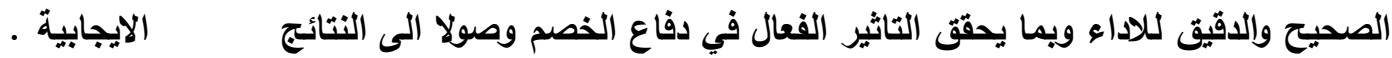

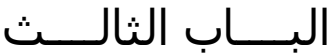

$$
\begin{aligned}
& \text { r- منهج البحث وإجراءاته الميدانية }
\end{aligned}
$$

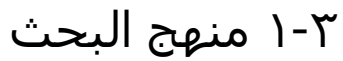

استخدم الباحثان المنهج التجريبي ذو تصميم المجموعتين المتكافئتين لملائمته مي طبيعة المشكلة المراد

$$
\text { r-r }
$$

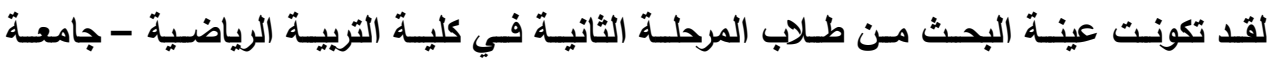

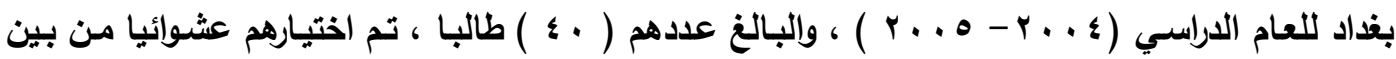

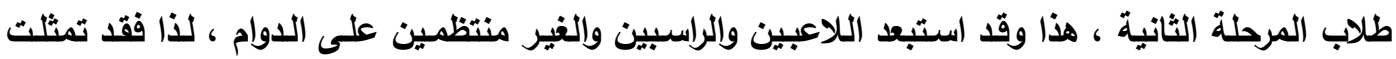

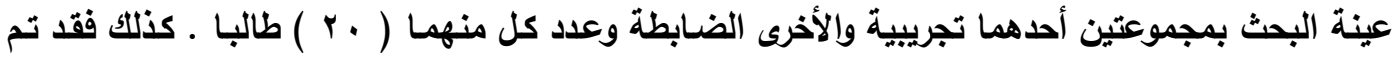
استخراج تكافؤ العينة باستخدام اختبار ( T ) لمعرفة الفروق بين المجموعتين ولاختبار الإرسـال المواجـه من الأعلى، وكما هو موضح في الجدول ( 1 ( ) .

$$
\text { جدول (1) }
$$

تكافؤ المجموعتين التجريبية والضابطة في اختبار الارسال المواجه من الاعلى

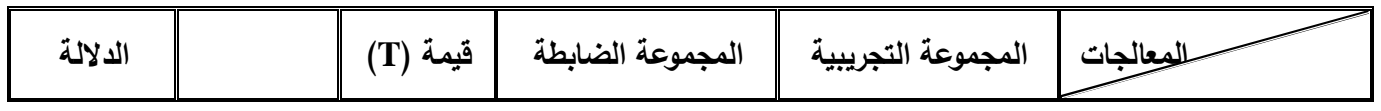

(1) Brents. Rushall: specificity of training transfer of training effects for skills rarelyoccur:in answer to guestions from dr.larry weisenthali, 1997, p.1, http:// www. 


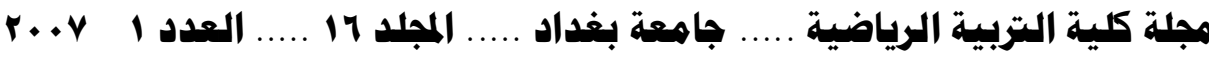

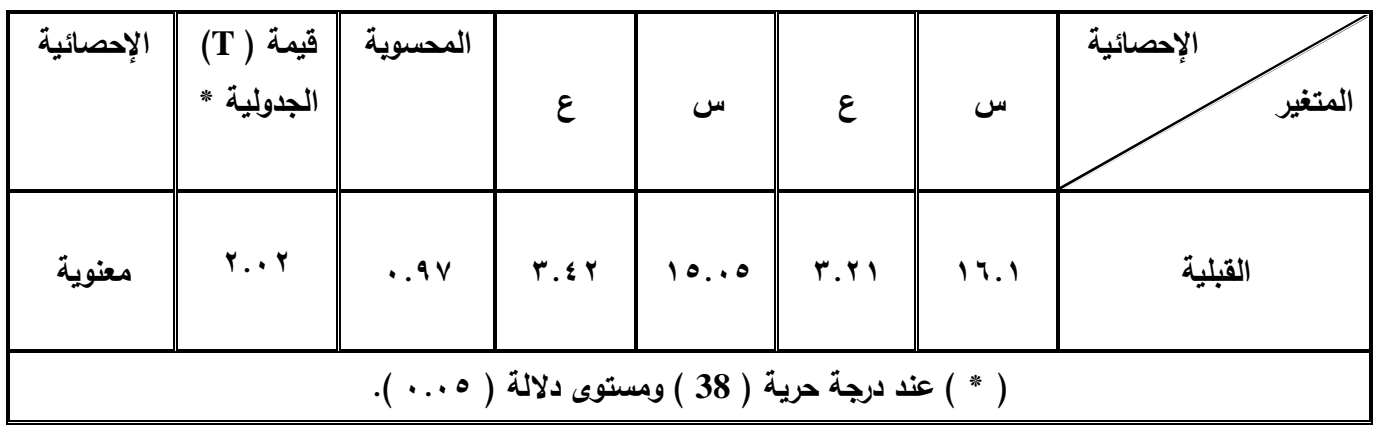

r-ץ الأدوات والأجهزة المستخدمة

تم الاستعانة بالأدوات التالية :

1. المصادر العربية والأجنبية .

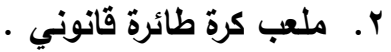

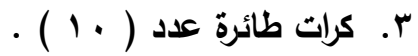

؛. شريط لاصق عرض ( 5cm ) .

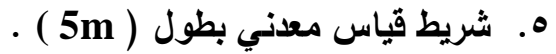

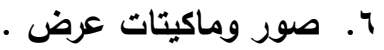

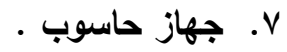

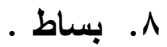

9. الاختبار والقياس.

r-ع الاختبارات المستخدمة

استخدم اختبار AAHPER(") ( ) لقياس دقة الإرسال المواجه من الأعلى ( التنس ) .

ب-0 التجربة الاستطلاعية

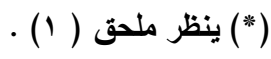

(1) محمد صبحي حسانين وحمدي عبد المنعم؛ الاسس العلمية للكرة الطائرة وطرق القياس والتقويم :( القاهرة، مركز الكتاب 


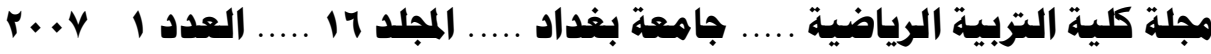

بهدف معرفة الجوانب السلبية والصعويات والمعوقات التي قد ترافق أجراء التجرية الرئيسية إلى

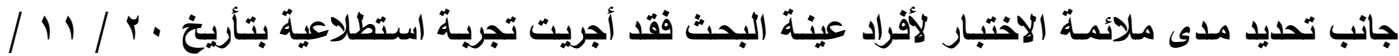

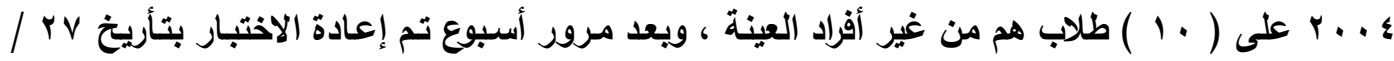

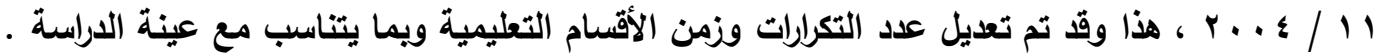

$$
\begin{aligned}
& \text { ب-7 إجراءات البحث الميدانية } \\
& \text { r-7-1 الاختبارات القبلية }
\end{aligned}
$$

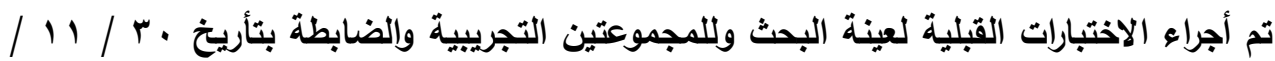

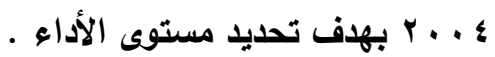

r-7-T طريقة تنفيذ التجربة الرئيسية تم تطبيت المنهج التـريسـي المستخدم في الكليـة والخـاص بـتعلم مهارة الإرسـال المواجـه مـن الأعلى ( التنس ) مـع إدخال التصور الذهني كمتغير تجريبي للوقوف على مستوى تأثيره في تعلم دقة الإرسال وللمجموعة التجريبية ، إذ أعطيت هذه المجموعة واجب تصوري كالقيام بأخذ الكرة واداء الإرسال من منطقة الإرسال إلى الساحة المقابلة وتصور أن الكرة تسقط في المنطقة التي تثبير إلى أعلى النقاط

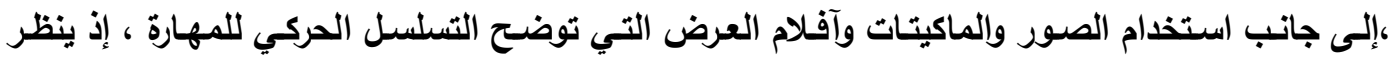
اليها الطالب بدقة ثم يطلب منـه الاسترخاء بعدها يتصور الحركـة في ذهنه ثم يطلب منهـ شرح الأداء

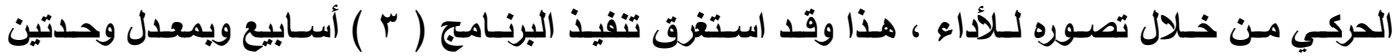

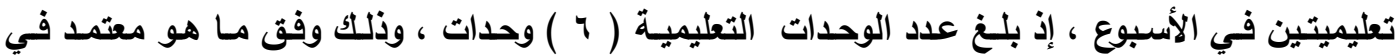
البرنامج الموضوع للمرحلة الثانية ، وقد بلغ زمن الوحدة التعليمية ( 9 ) دقيقة ولكـلا المجموعتين ، أمـا المجموعة الضابطة فقد طبق عليها المنهج التدريسي بشكله المعتمد.

$$
\text { r-ץ-ץ الاختبارات البعدية }
$$

بعـد الاتتهـاء مـن تنفيـذ المـنهج التعليمسي قـام الباحثـان بـأجراء الاختبـارات البعديـة بتــأريخ

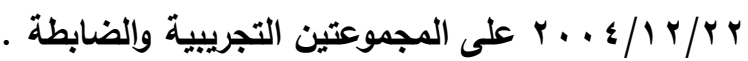




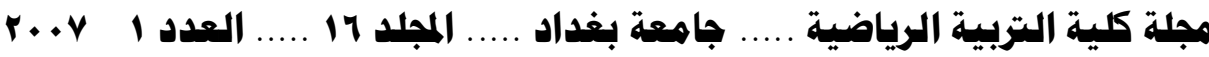

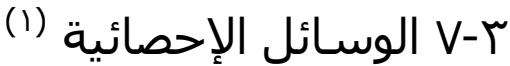

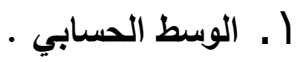

$$
\begin{aligned}
& \text { r. ب. الاتحراف المعياري. } \\
& \text { r. اختبار ( T T ) للعينات المتناظرة . } \\
& \text { ـ. اختبار ( T ) للعينات الغير متناظرة . }
\end{aligned}
$$

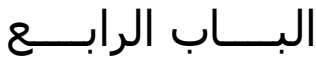

$$
\begin{aligned}
& \text { ع- عرض النتائج وتحليلها ومناقشتـابـا لعرضا } \\
& \text { ع-1 عرض النتائج }
\end{aligned}
$$

الجـدول (Y ) يبـين الاوســاط الحســابية والانحرافــات المعياريـة للاختبـاريين القبلـي والبعـدي للمجمـوعتين التجريبيـة والضـابطة ، وقيمـة (T) المحسويه والجدوليـة لاختبـار دقة الارسـال المواجـه مـن

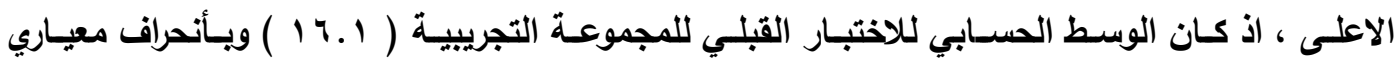

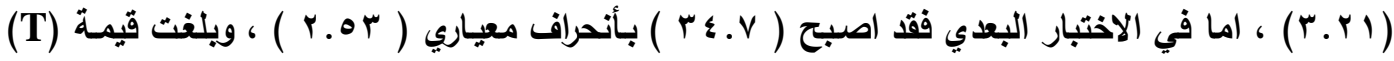

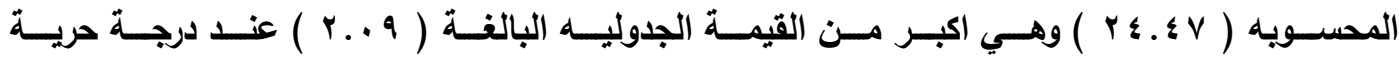

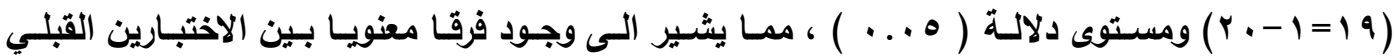
والبعدي ولصالح البعدي · البعال اما فيما يخص المجموعة الضـابطة وللاختبار نفسـه فقد كان الوسط الحسابي للاختبار القبلـي

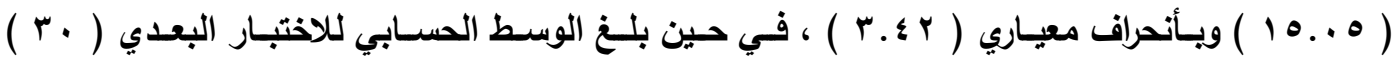

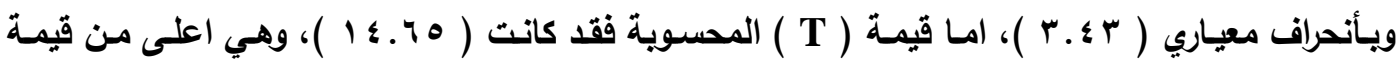

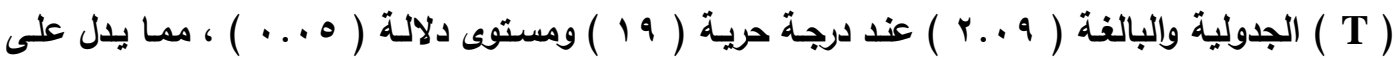
وجود فرقا معنويا بين الاختبارين ولصالح الاختبار البعدي .

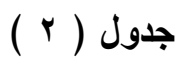

(1) وديع ياسين وحسن محمد ـ التطبيقات الاحصائية واستذدامات الحاسوب في بحوث التربية الرياضية : ( الموصل ، دار

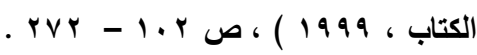




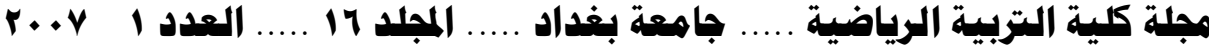

الوسط الحسابي والانحراف المعياري وقيمة ( T ) المحسوية والجدولية في الاختبارين القبلي والبعدي للمجموعتين التجريبية والضابطة لاختبار دقة الإرسال المواجه من الأعلى

\begin{tabular}{|c|c|c|c|c|c|c|c|}
\hline \multirow{2}{*}{ الإحصائية } & \multirow{2}{*}{ قالجدولية * } & \multirow{2}{*}{ قالمحسوية } & \multicolumn{2}{|c|}{ الاختبار البعدي } & \multicolumn{2}{|c|}{ الاختبار القبلي } & \multirow{2}{*}{ 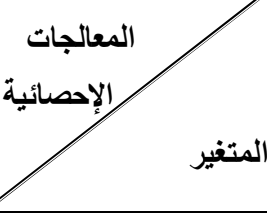 } \\
\hline & & & $\varepsilon$ & س & $\varepsilon$ & س & \\
\hline معنوية & \multirow{2}{*}{2.09} & $r \leq . \leq V$ & r.or & $r \varepsilon . v$ & r.r. & 14.1 & المجموعة التجريبية \\
\hline معنوية & & $1 \leq .70$ & $r . \leqslant r$ & $r$. & $r . \leqslant Y$ & $10 . .0$ & المجموعة الضابطة \\
\hline
\end{tabular}

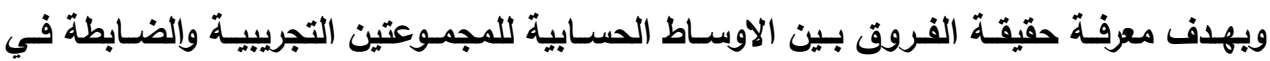

الاختبارات البعدية فقد استخدم اختبار ( T ) للعينات الغير متناظرة ، وكما هو مبين في الجدول ( ب ).

$$
\text { جدول ( ) (r) ) }
$$

الاوساط الحسابية والانحرافات المعيارية وحجم العينة وقيمة ( T ) المحسوية والجدولية للمجموعتين

\begin{tabular}{|c|c|c|c|c|c|c|c|}
\hline \multirow{2}{*}{ الإحصائية } & \multirow[t]{2}{*}{ 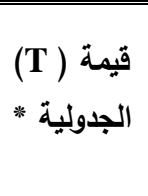 } & \multirow{2}{*}{ قيمة (T) } & \multicolumn{2}{|c|}{ المجموعة الضابطة } & \multicolumn{2}{|c|}{ التجريبية } & \multirow[t]{2}{*}{ الإحصائية } \\
\hline & & & $\varepsilon$ & س & $\varepsilon$ & س & \\
\hline معنوية & $r . . r$ & 纟.9 & $r . \leqslant r$ & $r$. & r.Or & $r \leqslant . V$ & البعدية \\
\hline
\end{tabular}

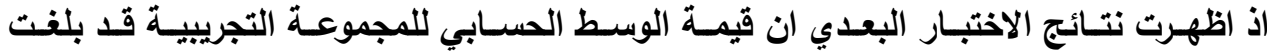

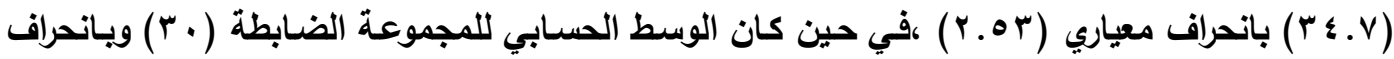

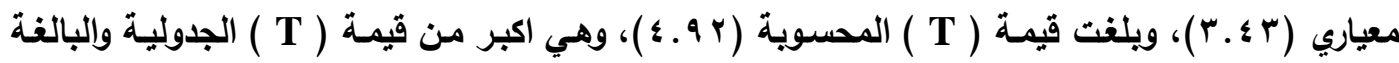

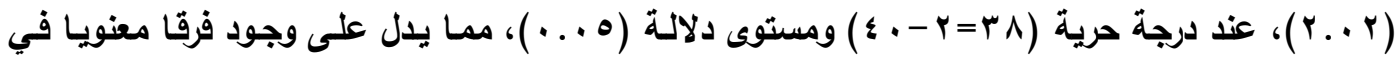
الاختبارات البعدية بين المجموعتين التجريبية والضابطة ولصالح المجموعة التجريبية . 


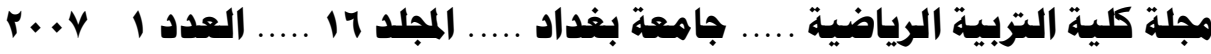

مـن خـلال النتـائج التـي تم عرضـها نجـا بـان المجمـوعتين التجريبيـة والضـابطة في الاختبـارات القبلية لم يكن هنالك فرق معنوي لكـلا المجموعتين وذلك مؤشر على ان مستوى الاداء كلان متقاربـا في كليهما.

وعند مقارنـة نتائج المجموعة التجريبيـة بالمجموعة الضـابطة في الاختبارات البعدية ظهر بـان المجموعة التجريبية قد حققت تطورا اكثر قياسـا بالمجموعة الضـابطة في مهارة الارسـال ويعزو الباحثان

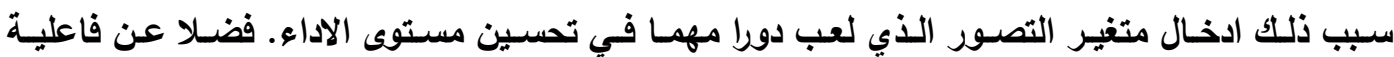
التمـارين المتنوعـة والمختلفـة التـي تـم تطبيقها في الوحدات التعليميـة، ممـا سـاعد على تنميـة التصـور لاتخاذ الوضع المناسب عند اداء مهارة الارسـال وتوجيه الكرة بشكل دقيق الى المناطق التي تضم اعلى لــ اللارجات، اذ ان " التصسور الحركي يزيــ مـن سـرعة اكتسـاب المهـارات الرياضية وتحسن ادائهـا ويعطي

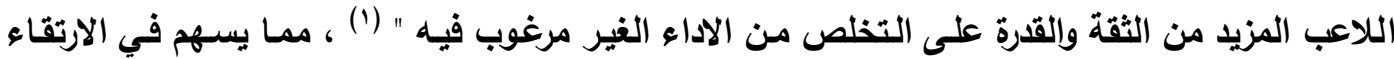

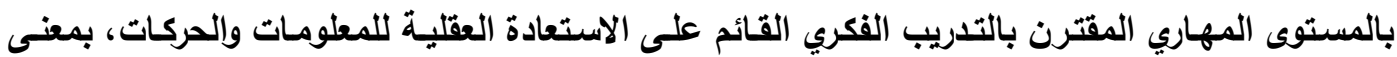
تصور الحركة وتحليلها ذهنيا لتحقيق نتائج ايجابية اثناء الاداء. كما وان استخدام الوسـائل المسـاعدة مـن صور وماكيتـات وغلق العينين اثر واضـح في تنميـة الاحسـاس بالمكان والتوقيت الذي يمثل نـاتج تطور القدرات الادراكية الحركية، اي ان " استخدام الوسـائل

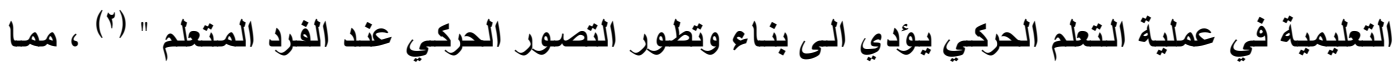
ينعكس ايجابيا في سرعة تعلمه وتطوره، اذ تتطلب مهارة الارسال من اللاعب المرسل تحديد ارتفاع الكرة ومسافاتها واتجاهها بهاف التاثير في دفاع الفريق المنافس ويما يحقى نتائج ايجابية .

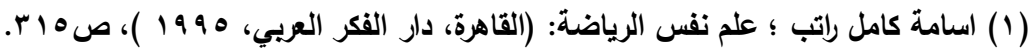

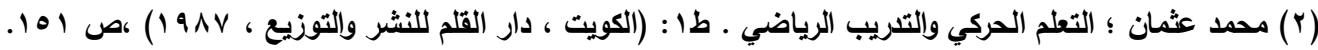




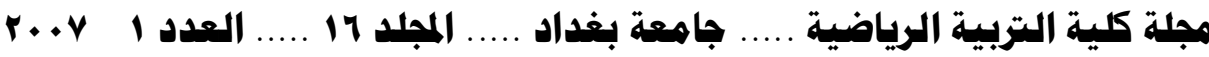

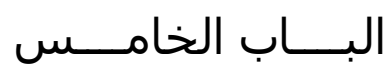

0- الاسـتنتاجات والتوصيات

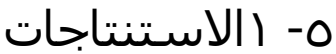

ضمن النتائج المتحققه تم التوصل الى الى الاستنتاجات الاتية : 1. التصور الذهني كان العامل الاساسي في تفوق المجموعة التجريبية على المجموعة الضـابطة في تعلم دقة الارسال المواجه من الاعلى بالكرة الطائرة .

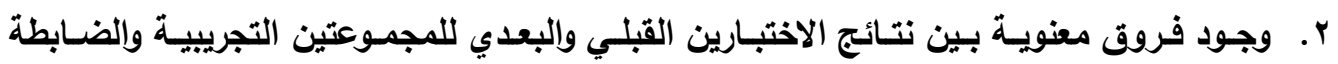
ولصالح الاختبار البعدي في تعلم دقة الارسال المواجه من الاعلى بالكرة الطائرة . r. ان استخدام التصور الذهني كان لـه الاثر الايجابي في تحسن دقة اداء مهارة الارسـال المواجهـ

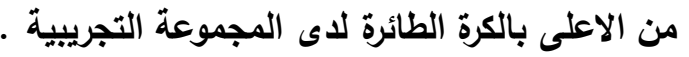

0 1. اعطاء بعض الوقت من زمن الوحدة التدريبية لممارسـة تمـارين التصور الذهني لتعزيز الجانب المهاري لاى الطلاب واللاعبين.

r. استخدام التصور الذهي من قبل الطلاب والتلاعبين والتاكيا عليه من قبل المدرسين وإلمدربين r. ايجاد الوسائل الملائمة والسهلة والجيدة للتمرين على التصور الذهني ومحاولـة تحسينه وتطويره لاى الطلاب والللاعبين .

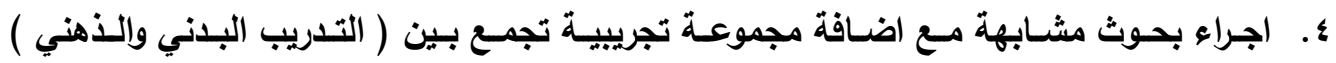
ومقارنتها مع نتائج مجموعة التدريب الذهني فقط . 


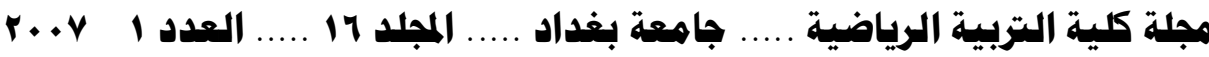

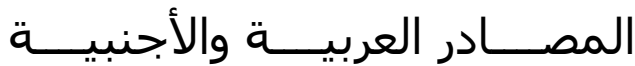

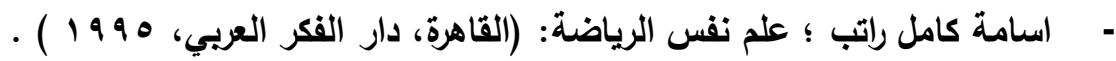

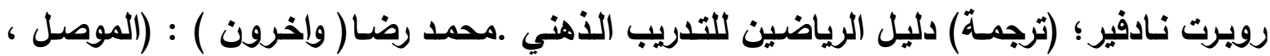

مطبعة دار الحكمة للطباعة والنشر ، . 99 (1).

- محمد عثمـان ؛ التعلم الحركي والتدريب الرياضس ـ طا : (الكويت ، دار القلم للنشر والتوزيع ،

.$(19 \wedge \mathrm{V}$

- - محد صبحي حسانين وحمدي عبد المنعم؛ الاسس العلمية للكرة الطائرة وطرق القياس والتقويم

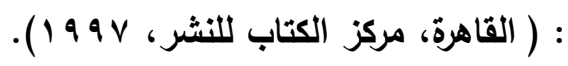

وجيه محجوب واخرون ؛ نظريات التعلم والتطور الحركي.طץ (بغداد، دار الكتاب، . . . ب).

وديـع ياسـين وحسن محمــ ؛التطبيقـات الاحصـائية واسـتخدامات الحاسـوب فـي بحسوث التربيـة

$$
\text { الرياضية:( الموصل، دار الكتاب، و9 } 999 \text { 1) ). }
$$

- Mccaffery\& orlick0,T .Mental factors related to excellence among top professional golfers.international journal of sport psychology.

- Brents. Rushall: specificity of training transfer of training effects for skills rarelyoccur:in answer to guestions from dr.larry weisenthali, 1997, http:// www. 


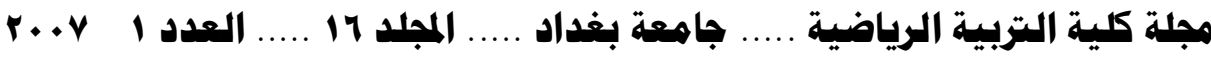

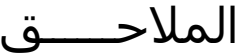

ملحق (1)

اختبار دقة الارسال

الغرض من الاختبار : قياس دقة مهارة الارسال لاى لاعب الكرة الطائرة في موقف مشابه للمبارة .

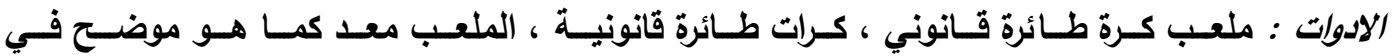

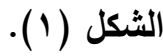

مواصفات الاداء : يقف اللاعب في منتصف خط نهايـة الملعب ( النصف المواجه لنصف الملعب المخطط على بعد (9) امتار من الشبكة ).

في هذا المكان والللاعب ممسك بالكرة يقوم بالارسال لتعبر الكرة الشبكة الى نصف الملعب

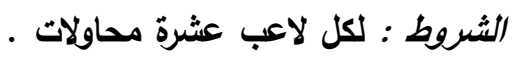

التسجيل : يحسب لكل مرة ارسال صحيح رقم المنطقة التي تهبط فيها الكرة في نصف الملعب المخطط ،

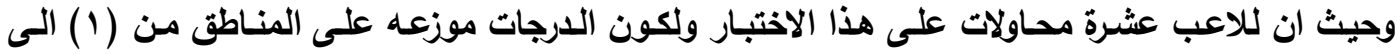

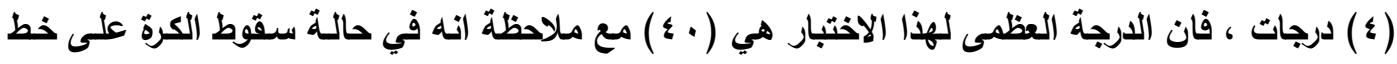
يفصل بين منطقتين يحسب للاعب درجة المنطقة الاعلى . 


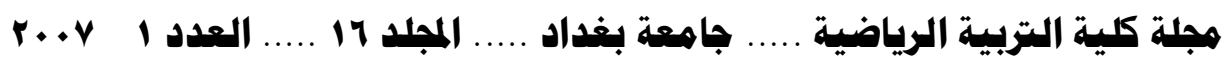

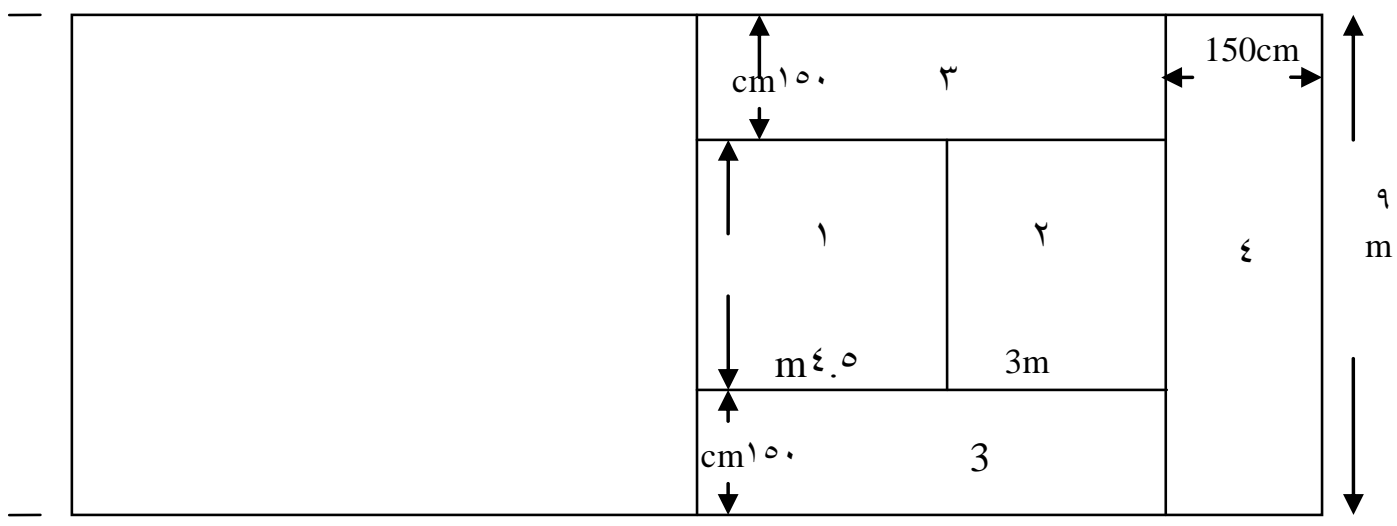

شكل (1)

اختبار دقة الإرسال 